\title{
Efeito de diferentes formas de cultivo na ação do óxido nítrico na maturação e na integridade da membrana plasmática de complexos cumulus-oócito em bovinos
}

\author{
Influence of different forms of culture on the nitric oxide action on maturation and \\ membrane integrity on bovine cumulus-oocyte complex
}

\author{
Kelen Salaroli VIANA ${ }^{1}$; Maria Clara CALDAS-BUSSIERE ${ }^{1}$; Carla Sobrinho Paes de CARVALHO ${ }^{1}$; \\ Bruna Lomba DIAS'; Verônica R. LANES ${ }^{2}$; Celia Raquel QUIRINO ${ }^{1}$ \\ ${ }^{1}$ Laboratório de Reprodução e Melhoramento Genético Animal do Centro de Ciências e Tecnologias Agropecuárias da
Universidade Estadual do Norte Fluminense, Campos dos Goytacazes-RJ, Brasil
}

${ }^{2}$ Laboratório de Biologia do Reconhecer do Centro de Biociências e Biotecnologia da Universidade Estadual do Norte Fluminense, Campos dos Goytacazes-RJ, Brasil

\begin{abstract}
Resumo
O objetivo do presente estudo foi avaliar se diferentes formas de cultivo interferem no efeito do óxido nítrico (NO) sobre a maturação e a integridade da membrana plasmática do complexo cumulus-oócito de bovinos. Para tanto, realizou-se cultivo em gotas sob óleo mineral ou em placas de quatro poços com a adição de diferentes concentrações de nitroprussiato de sódio (SNP, doador de óxido nítrico). Não foi observada diferença $(\mathrm{P}>0,05)$ entre as formas de cultivo quando se avaliou a integridade de membrana plasmática e a expansão das células do cumulus (CC). Contudo, os oócitos dos grupos controle e os cultivados na presença de $10^{-3} \mathrm{M}$ de SNP, ambos cultivados em placa, apresentaram maior porcentagem de membrana íntegra do que os mesmos tratamentos cultivados em óleo mineral $(\mathrm{P}<0,05)$. Observou-se que a adição de $10^{-3} \mathrm{M}$ de SNP diminuiu o grau de expansão das CC e de integridade da membrana plasmática dos oócitos, tanto no cultivo em gota sob óleo quanto em placa, diferindo dos outros grupos $(\mathrm{P}<0,05)$. Semelhante à expansão, a forma de cultivo não interferiu na extrusão do primeiro corpúsculo polar, sendo que a adição de $10^{-3} \mathrm{M}$ de SNP inibiu a extrusão em ambos os sistemas $(\mathrm{P}<0,05)$. Houve um efeito dose-resposta na concentração de NO no meio de maturação em ambos os tipos de cultivo $(\mathrm{P}<0,05)$, sendo que esta foi maior no meio de cultivo sob óleo, exceção feita quando se adicionou $10^{-3} \mathrm{M}$ de SNP, tratamento no qual não houve diferença nos tipos de cultivo empregados. Estes dados mostram que o sistema de cultivo não interferiu na ação do NO na maturação in vitro de COC bovinos, mas interfere na integridade da membrana plasmática do oócito.
\end{abstract}

Palavras-chave: Óxido nítrico. Óleo mineral. Maturação in vitro. Nitroprussiato de sódio. Cultivo in vitro. Bovino..

\begin{abstract}
The aim of the present study was to evaluate the influence of different forms of in vitro culture on the nitric oxide action in maturation and membrane integrity on bovine cumulus-oocyte complex. No significant effect was observed between different forms of culture (mineral oil vs plate; P > 0.05), as much for membrane integrity as for expansion of the CC. However, it was observed that oocytes of the groups control and $10^{-3} \mathrm{M}$ of SNP, cultivated in plate, had presented greater percentage of cell with maintenance of membrane integrity than same treatments cultivated in drop. The addition of $10^{-3} \mathrm{M}$ of SNP showed an inhibitory effect on the expansion and membrane integrity of CC and oocytes in both, culture in drops under oil and plate $(\mathrm{P}<0.05)$. The culture form did not intervene with the extrusion of the first polar corpuscle and the addition of $10^{-3} \mathrm{M}$ of SNP inhibited this extrusion in the both systems $(\mathrm{P}<0.05)$. There was a dose-response effect on the concentration of NO in the maturation medium in both types of cultivation $(\mathrm{P}<0,05)$, and this was higher in the culture medium under oil, except when added $10^{-3} \mathrm{M}$ of SNP, treatment in which there was no difference in the types of cultivation employed. $(\mathrm{P}<0.05)$. These data demonstrate that the culture system did not intervene with the action of the $\mathrm{NO}$ in the maturation in vitro of bovine $\mathrm{COC}$, but intervened with the integrity of the plasmatic membrane of the oocyte.
\end{abstract}

Keywords: Nitric oxide. Mineral oil. In vitro maturation. Sodium nitroprusside. In vitro culture. Bovine.

Correspondência para:

Kelen Salaroli Viana,

Universidade Estadual do Norte Fluminense Darcy Ribeiro

Setor de Biotecnologia da Reprodução

Av. Alberto Lamego, 2000, Pq. Califórnia,
CEP: 28013-602 - Campos dos Goytacazes, RJ, Brasil

e-mail: kelensv@uenf.br

Recebido: 01/03/2010

Aprovado: 09/02/2011 


\section{Introdução}

$\mathrm{O}$ óxido nítrico $(\mathrm{NO})$ é um gás altamente reativo e com meia-vida curta. É rapidamente oxidado para nitrato $\left(\mathrm{NO}_{3}^{-}\right)$e nitrito $\left(\mathrm{NO}_{2}^{-}\right)$, dois produtos estáveis do metabolismo do NO. O NO é um importante mensageiro inter e intracelular, envolvido em várias etapas da reprodução como esteroidogênese ${ }^{1}$, integridade da membrana plasmática de células do cumulus $^{2}$, de células da granulosa de folículos antrais ${ }^{1}$ e de espermatozoides ${ }^{3}$, além da sobrevivência folicular, ovulação, fecundação e implantação embrionária ${ }^{4}$.

Foi demonstrado que a adição de $10^{-5} \mathrm{M}$ de nitroprussiato de sódio (SNP, doador de NO) aumentou a taxa de produção de blastocistos bovinos produzidos in vitro ${ }^{5}$, enquanto $10^{-3} \mathrm{M}$ de SNP diminuiu a expansão das CC e a maturação nuclear ${ }^{5}$. Viana et al..$^{5}$ sugeriram que este efeito deletério possa ter sido mediado pela ação do NO na integridade da membrana plasmática, levando a uma alteração na funcionalidade das CC e do oócito. A comunicação intercelular entre oócitos e células do cumulus (CC) no estádio de vesícula germinativa é essencial para promover a maturação dos oócitos, a qual é crucial para fertilização e desenvolvimento embrionário ${ }^{6}$. Já foi demonstrado que a remoção das CC antes da maturação suprime a maturação oocitária ${ }^{7}$. As CC podem refletir a qualidade do oócito e são frequentemente usadas para seleção de COC. A função mais visível das CC é sua habilidade de uma rápida expansão da matriz extracelular. A perda da funcionalidade das CC, que pode ser caracterizada pela inibição da expansão, pode interferir diretamente no processo de maturação oocitária.

A maturação in vitro (MIV) de oócitos é comumente realizada usando gotas de meio de cultivo cobertas com óleo mineral ${ }^{8,9}$. Estudos recentes têm realizado cultivo em placa de quatro poços, utilizando um maior volume de meio de maturação, aumentando-se a relação do número de oócitos/volume de meio de cultivo. Esse tipo de sistema de cultivo dispensa a utilização do óleo mineral, além de aumentar a disponibilidade de nutrientes e diminuir o estresse causado pela liberação de toxinas produzidas pelo COC durante a maturação ${ }^{10,11}$. O óleo mineral possui alta capacidade em absorver substâncias lipossolúveis presentes no meio de cultivo, podendo alterar a concentração de substâncias importantes no processo de maturação do COC e integridade de membranas plasmáticas do oócito e $\mathrm{CC}^{12}$. No tradicional sistema de MIV, o cultivo de COC em meio coberto com óleo mineral pode estar limitando a capacidade de desenvolvimento dos oócitos maturados in vitro.

Sendo assim, o objetivo do presente estudo foi avaliar se o efeito do NO sobre a maturação e a integridade da membrana plasmática do complexo cumulusoócito de bovinos após a adição de concentração média $\left(10^{-5} \mathrm{M}\right)$ e alta $\left(10^{-3} \mathrm{M}\right)$ de SNP, no meio de cultivo em gota ( $150 \mu \mathrm{L}$ de meio coberta com óleo), poderia ser minimizado em relação aos efeitos observados no COC cultivado em placa de quatro poços $(500 \mu \mathrm{L}$ de meio) pelo fato do NO ser um gás difusível e lipolítico.

Material e Método

Todos os reagentes utilizados foram provenientes da Sigma-Aldrich (St. Louis, MO, USA), exceto os mencionados no texto. Ovários de vacas mestiças cíclicas, após terem sido obtidos em abatedouros, foram colocados em frascos contendo solução salina e antibiótico em temperatura de $37^{\circ} \mathrm{C}$. Os folículos foram aspirados usando seringa de $10 \mathrm{~mL}$ e os complexos cumulus-oócito (COC) imediatamente colocados em meio de lavagem [TCM 199-HEPES acrescido de 5\% de soro fetal bovino (SFB) e antibióticos (100 UI/mL de penicilina e $100 \mathrm{UI} / \mathrm{mL}$ de estreptomicina - Merck, Darmstadt, Germany)]. A este meio foi adicionado 3-isobutil-1-metil-xantina (IBMX, 0,5 mM) para manter o bloqueio da meiose durante o período de manipulação dos mesmos. Somente os COC que apresentavam mais de três camadas de CC e ooplasma homogêneo foram selecionados. 
Foram utilizados 30 COC para cada repetição em todos os tratamentos e cada experimento foi repetido quatro vezes. Oócitos selecionados foram distribuídos aleatoriamente em gotas de $150 \mu \mathrm{L}$ de meio de maturação [TCM 199 suplementado com 10\% de SFB, 0,5 $\mu \mathrm{g} /$ $\mathrm{mL}$ de FSH (Folltropin-V, Bioniche, Beleville, Canadá), $5 \mu \mathrm{g} / \mathrm{mL}$ de LH (Lutropin-V, Bioniche, Beleville, Canadá), e antibióticos citados acima], cobertas com óleo mineral ou em placas de cultura celular com quatro poços (Ingámed Materiais Hospitalares, Perobal/PR, Brasil) com $500 \mu \mathrm{l}$, sendo ambos experimentos mantidos por $24 \mathrm{~h}$ em estufa a $38,5^{\circ} \mathrm{C}$, em atmosfera de $5 \%$ de $\mathrm{CO}_{2}$. Os tratamentos consistiram da adição de 0 (controle), $10^{-5}$ e $10^{-3} \mathrm{M}$ de SNP diluídos em meio de maturação de acordo com Viana et al. ${ }^{5}$.

O grau de expansão do cumulus foi avaliado $24 \mathrm{~h}$ após o início da maturação in vitro, utilizando um método de classificação subjetiva proposto por Tao et al. ${ }^{13}$ : Grau 1 (G 1) - reposta mínima; Grau 2 (G 2) - expansão das camadas externas; Grau 3 (G 3)- expansão de todas as camadas, exceto da corona radiata e Grau 4 (G 4) - expansão de todas as camadas.

Foi utilizado o método de coloração dupla para avaliar a integridade da membrana plasmática das CC: brometo de etídio (BE), o qual marca o núcleo de células que apresentam membrana lesada (cor vermelha), e laranja de acridina (LA), o qual marca o DNA de células vivas (cor verde). Ambos corantes foram diluídos na concentração de $1 \mathrm{mg} /$ mL. Para cada $100 \mu \mathrm{L}$ de PBS suplementado com $5 \%$ de SFB, $10 \mu \mathrm{L}$ da solução contendo os dois corantes (1:1) diluídos em PBS foram adicionados. Após o período de maturação, os COC foram desnudos mecanicamente, os oócitos foram retirados do meio e as CC centrifugadas $(700 \mathrm{x} \mathrm{g}$ ) por 10 min e ressuspensas em PBS com 5\% de SFB contendo os corantes. As células foram colocadas entre lâmina e lamínula, levadas ao microscópio de epifluorescência (400x) (NIKON - Eclipse TE300/ TE200, Melville, N.Y., USA) para contagem (200-
250 células de cada tratamento). O meio de maturação foi coletado e estocado a $-20{ }^{\circ} \mathrm{C}$ para futura dosagem de NO.

Para observação da integridade da membrana plasmática dos oócitos foi utilizada marcação dupla com Hoechst 33342 e iodeto de propídeo (IP). Após o período de maturação, os oócitos foram desnudos e expostos ao Hoechst $33258(10 \mu \mathrm{g} / \mathrm{mL})$ por 5 min e após este período, ao IP $(5 \mu \mathrm{g} / \mathrm{mL})$ por $5 \mathrm{~min}$. Os oócitos foram colocados entre lâmina e lamínula com glicerol e observados individualmente com auxílio do microscópio (NIKON - Eclipse TE300/TE200, Melville, N.Y., USA)(400x). Os oócitos foram classificados em dois grupos: 1) com membrana plasmática íntegra, apresentando núcleo corado em azul (marcado com Hoechst) e 2) com perda da integridade da membrana plasmática, apresentando núcleo corado em vermelho (marcado com IP).

A extrusão do primeiro corpúsculo polar (CP) foi avaliada pela coloração com Hoechst 33342 $(10 \mu \mathrm{g} / \mathrm{mL})$ por $5 \mathrm{~min}$. Os oócitos foram classificados como: com CP e sem CP. A concentração de nitrato/nitrito $\left(\mathrm{NO}_{3}^{-} / \mathrm{NO}_{2}^{-}\right)$, metabólitos estáveis do NO, foi determinada pelo método baseado na reação colorimétrica de Griess ${ }^{2,14}$. As análises foram realizadas em espectofotômetro (Multiskan EX Primary EIA V 2.1-0).

Os dados foram avaliados usando o SAS (Statistical Analysis System, Cary, NC, USA) pela análise de variância (ANOVA) para verificar se o sistema de cultivo (gotas cobertas com óleo - $150 \mu \mathrm{L}$ e placa de quatro poços - $500 \mu \mathrm{L})$ interfere no efeito do $\mathrm{NO}\left(10^{-5}\right.$ e $10^{-3}$ M de SNP) na maturação e na integridade da membrana plasmática dos COC. As médias foram comparadas pelo teste $t$ a $5 \%$ de probabilidade.

\section{Resultados}

O grau de expansão dos COC do grupo controle e do grupo tratado com $10^{-5} \mathrm{M}$ de SNP foi semelhante 
nos dois tipos de cultivo, contudo, a percentagem de COC que apresentou expansão mínima aumentou $(\mathrm{P}<0,05$; Tabela 1 e Figura 1$)$ quando se adicionou $10^{-3} \mathrm{M}$ de SNP no meio de cultivo, tanto em gota coberta com óleo, (69 $\pm 10,4 \%$ em G1) como em placa de quatro poços $(61,2 \pm 7,2 \%$ em G1) quando comparado com o controle, onde não houve a presença de COC em G1 (Tabela 1).

Não houve diferença na integridade de membrana das células do cumulus quando os diferentes tipos de cultivo foram comparados ( $\mathrm{P}>0,05$, Figura 1 e Tabela 2). Quando se avaliou o efeito do tratamento, a adição de $10^{-3} \mathrm{M}$ de SNP promoveu uma diminuição no número de células com membrana íntegra em ambos os tipos de cultivo $(0,75 \pm 0,5 \%$ das CC e 6,7 $\pm 2,8 \%$ dos oócitos IP (-) no cultivo em óleo e $0,5 \pm$ 0,5\% das CC e 19,3 \pm 8,2\% dos oócitos IP (-) no cultivo em placa; $\mathrm{P}<0,05$; Tabela 2).

O cultivo em placa apresentou uma maior porcentagem de oócitos com membrana íntegra (oócitos IP -) tanto no grupo controle $(91,8 \pm 3,1 \%$ no cultivo em óleo e $100 \pm 0,0 \%$ no cultivo em placa) quanto no grupo com $10^{-3} \mathrm{M}$ de SNP $(6,7 \pm 2,8 \%$ no cultivo em óleo e 19,3 $\pm 8,1 \%$ no cultivo em placa; $\mathrm{P}<0,05)$.

Tabela 1 - Efeito da adição de diferentes concentrações de SNP durante a maturação in vitro de oócitos bovinos na expansão das CC em diferentes formas de cultivo

\begin{tabular}{ccccccc}
\hline $\begin{array}{c}\text { Tratamento/ } \\
\text { SNP }\end{array}$ & Controle & $10^{-5} \mathrm{M}$ & $10^{-3} \mathrm{M}$ & Controle & $10^{-5} \mathrm{M}$ & $10^{-3} \mathrm{M}$ \\
\hline $\mathrm{G} 1$ & $0^{\mathrm{b}}$ & $0^{\mathrm{b}}$ & $69,7 \pm 10,4^{\mathrm{a}}$ & $0^{\mathrm{b}}$ & $0^{\mathrm{b}}$ & $61,2 \pm 7,2^{\mathrm{a}}$ \\
$\mathrm{G} 2$ & $0^{\mathrm{b}}$ & $0^{\mathrm{b}}$ & $30,3 \pm 10,4^{\mathrm{a}}$ & $0^{\mathrm{b}}$ & $0^{\mathrm{b}}$ & $38,8 \pm 7,2^{\mathrm{a}}$ \\
$\mathrm{G} 3$ & $24,7 \pm 19,3^{\mathrm{b}}$ & $37 \pm 6,3^{\mathrm{b}}$ & $0^{\mathrm{a}}$ & $13,8 \pm 10,1^{\mathrm{b}}$ & $12,7 \pm 9,8^{\mathrm{b}}$ & $0^{\mathrm{a}}$ \\
$\mathrm{G} 4$ & $75,2 \pm 19,3^{\mathrm{b}}$ & $63 \pm 6,2^{\mathrm{b}}$ & $0^{\mathrm{a}}$ & $86,3 \pm 10,1^{\mathrm{b}}$ & $87,3 \pm 9,1^{\mathrm{b}}$ & $0^{\mathrm{a}}$ \\
\hline
\end{tabular}

O grau de expansão foi observado $24 \mathrm{~h}$ após o período de cultivo. Foi utilizado um sistema de escala subjetivo de 1 a 4 descritos a seguir: grau 1 (G 1) - reposta mínima; grau 2 (G 2) - expansão das camadas externas; grau 3 (G 3)- expansão de todas as camadas, exceto da corona radiata e grau 4 (G 4) expansão de todas as camadas. ${ }^{\mathrm{a}-\mathrm{b}}$ Letras diferentes na mesma linha indicam diferença entre tratamentos $(\mathrm{P}<0,05)$. Foram utilizados 30 COC para cada repetição. Os dados são apresentados como média $\pm \mathrm{SD}$ da percentagem de quatro repetições.

Tabela 2 - Integridade de membrana das células do cumulus/oócito e extrusão do primeiro corpúsculo polar de COC cultivados em diferentes formas de cultivo (em gotas cobertas com óleo ou em placas de quatro poços) com adição de diferentes concentrações de SNP no meio de cultivo

\begin{tabular}{|c|c|c|c|}
\hline Tratamento & Controle & $10^{-5} \mathrm{M}$ & $10^{-3} \mathrm{M}$ \\
\hline \multicolumn{4}{|c|}{ Brometo de etídeo negativo (\% - CC) } \\
\hline Óleo & $70,2 \pm 7,5 \mathrm{a}$ & $76,1 \pm 13,4 a$ & $0,75 \pm 0,5 b$ \\
\hline Placa & $77,6 \pm 11,5 a$ & $81,4 \pm 8,0 a$ & $0,5 \pm 0,5 b$ \\
\hline \multicolumn{4}{|c|}{ Iodeto de propídeo negativo (\% - oócitos) } \\
\hline Óleo & $91,8 \pm 3,1 \mathrm{bA}$ & $97,2 \pm 3,3 \mathrm{cA}$ & $6,7 \pm 2,8 \mathrm{aA}$ \\
\hline Placa & $100,0 \pm 0,0 \mathrm{bB}$ & $100,0 \pm 0,0 \mathrm{bA}$ & $19,3 \pm 8,1 \mathrm{aB}$ \\
\hline \multicolumn{4}{|c|}{ Extrusão CP (\% - oócitos) } \\
\hline Óleo & $64,6 \pm 5,1 \mathrm{aA}$ & $67,2 \pm 3,1 \mathrm{aA}$ & $0,0 \pm 0,0 \mathrm{bA}$ \\
\hline Placa & $69,5 \pm 7,5 \mathrm{aA}$ & $74,5 \pm 7 \mathrm{aA}$ & $0,0 \pm 0,0 \mathrm{bA}$ \\
\hline
\end{tabular}

Letras minúsculas na mesma linha indicam diferença entre os tratamentos $(\mathrm{P}<0,05)$; Letras maiúsculas na mesma coluna indicam diferença entre tipo de cultivo. Os dados são apresentados como média \pm SD de quatro repetições em percentagem. Foram utilizados 30 COC para cada repetição, sendo contadas 200 a 250 células do cumulus em cada tratamento; BE (-) e IP (-) = células com membrana plasmática íntegra (CC e oócito, respectivamente); $\mathrm{CP}=$ corpúsculo polar 

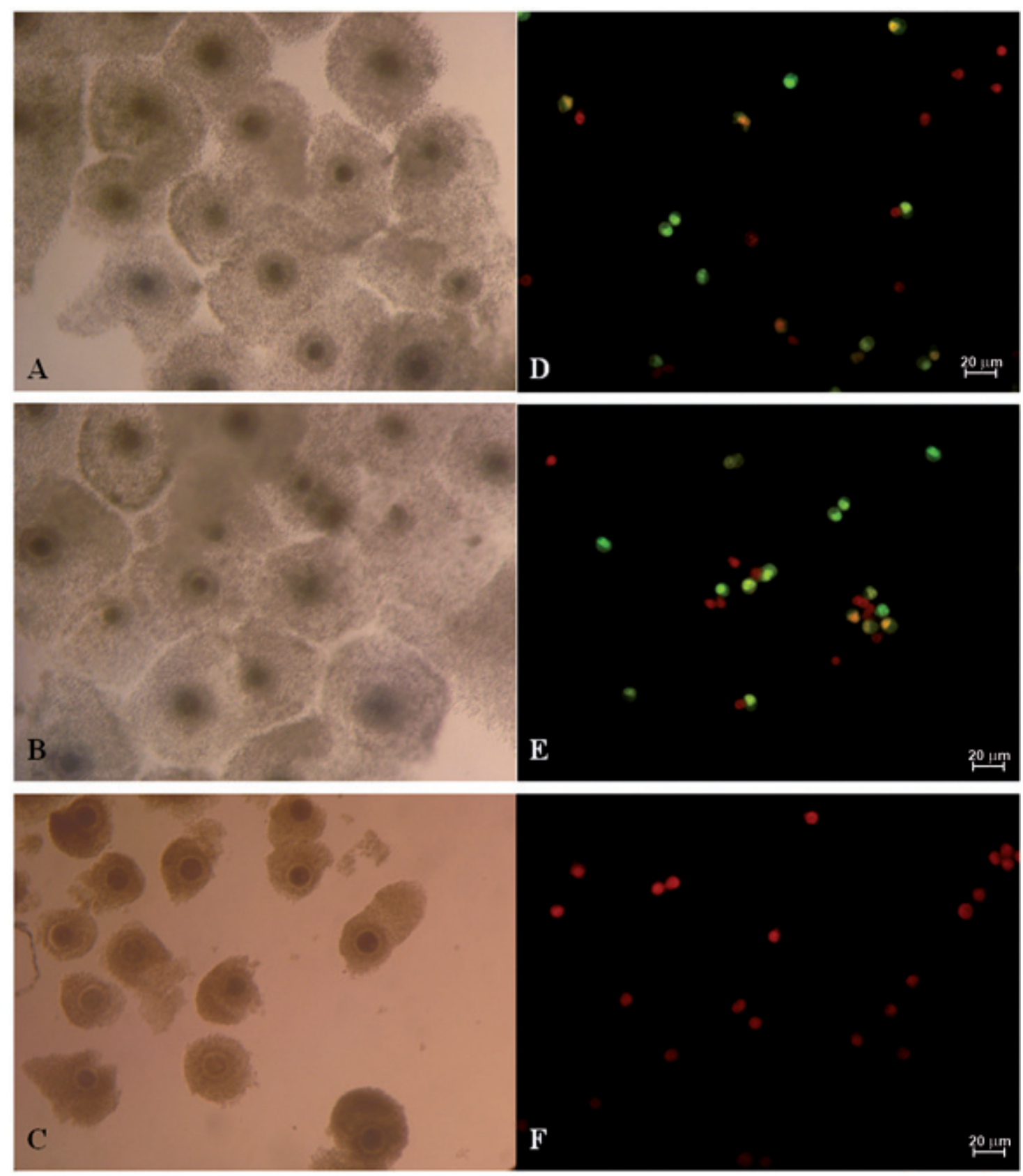

Figura 1 - Fotomicrografia representativa da expansão e integridade de membrana das células do cumulus. De A a C: Expansão das células do cumulus de COC cultivados em 0 (A - controle), $10^{-5}$ (B) e $10^{-3} \mathrm{M}$ de SNP (C). De D a F: Integridade das células do cumulus de COC cultivados na ausência de SNP (D - controle) e após a adição de $10^{-5}$ (E) e $10^{-3} \mathrm{M}$ de SNP (F). Células marcadas em vermelho (brometo de etídio) indicam células com perda da integridade de membrana e em verde (laranja de acridina) indicam células com membrana íntegra. Células do cumulus de cada tratamento mostraram comportamento semelhante nas diferentes formas de cultivo. As CC mostradas são de COC cultivados em placas

Tal diferença não foi observada no grupo $10^{-5} \mathrm{M}$ de SNP $(97,2 \pm 3,3 \%$ no cultivo em óleo e $100 \pm 0,0 \%$ no cultivo em placa; Tabela 2).
A forma de cultivo não interferiu na percentagem de oócitos que apresentaram extrusão do primeiro corpúsculo polar (CP; $\mathrm{P}>0,05)$, porém foi observada 
uma inibição da extrusão do CP quando se adicionou $10^{-3} \mathrm{M}$ de SNP $(\mathrm{P}<0,05)$ em ambas formas de cultivo (Tabela 2).

Houve um efeito dose-resposta crescente na concentração de NO no meio de maturação após 24 h em ambas formas de cultivo $(\mathrm{P}<0,05)$, sendo que esta foi maior no meio de cultivo em óleo mineral, exceto quando foi adicionado $10^{-3} \mathrm{M}$ de SNP, no qual não houve diferença nas diferentes formas de cultivo ( $\mathrm{P}>$ 0,05; Figura 2).

\section{Discussão}

No presente estudo, foi observado que COC do grupo controle e $10^{-5} \mathrm{M}$ de SNP apresentaram expansão semelhante nos dois tipos de cultivo, gota coberta com óleo e placa. Porém, essa expansão foi inibida quando se adicionou $10^{-3} \mathrm{M}$ de SNP no meio de cultivo tanto no cultivo em óleo quanto no em placa, corroborando com os resultados observados por Viana et al. ${ }^{5}$ nos quais foi observada uma diminuição do grau de expansão das células do cumulus de COC cultivados em óleo mineral utilizando-se a mesma concentração desse doador de NO. Esses dados mostram que o efeito na expansão das CC pela adição de $10^{-3} \mathrm{M}$ de SNP no meio se manteve mesmo sendo utilizada uma proporção maior oócito/meio (1 oócito/16,7 $\mu \mathrm{L}$ de meio) em relação à observada no cultivo em óleo (1 oócito/ $5 \mu \mathrm{L}$ de meio), sendo também independente da presença de óleo no meio de cultivo.

Além disso, foi observado que após o período de maturação, o meio de cultivo dos COC na gota com óleo dos grupos controle e $10^{-5} \mathrm{M}$ de SNP apresentaram coloração alterada, perdendo sua aparência rósea

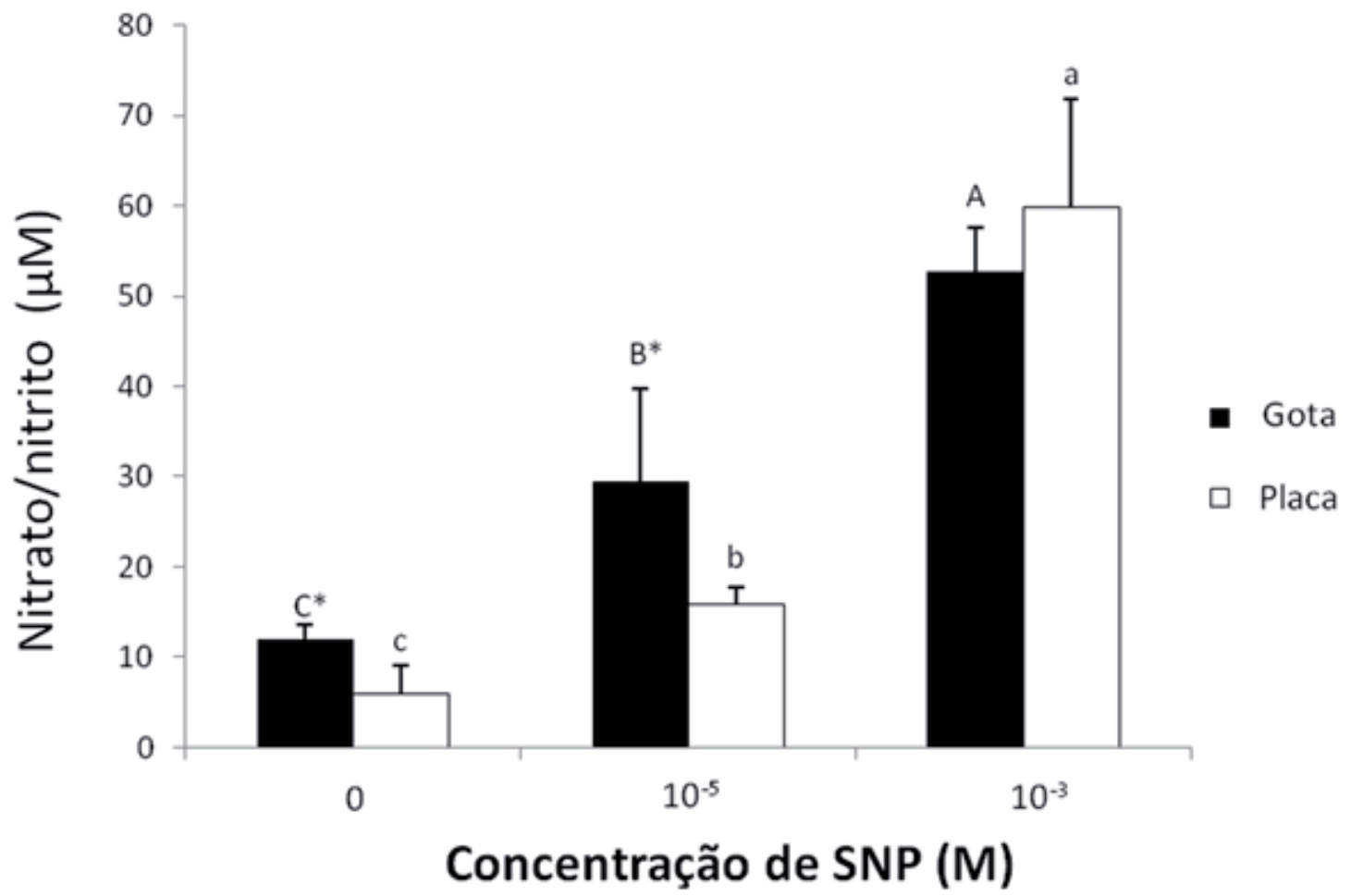

Figura 2 - Concentração de NO no meio de maturação in vitro de complexos cumulus-oócito $(\mathrm{n}=30)$ cultivados em gota $(150 \mu \mathrm{L})$ coberta com óleo mineral e placa de quatro poços $(500 \mu \mathrm{L})$. Médias seguidas por letras maiúsculas diferentes $(\mathrm{A}-\mathrm{C})$ mostram diferença $(\mathrm{P}<0,05)$ para cada tratamento cultivado em gota. Médias seguidas por letras minúsculas diferentes $(\mathrm{a}-\mathrm{c})$ mostram diferença $(\mathrm{P}<0,05)$ para cada tratamento cultivado em placa. $\left(^{*}\right)=$ diferença entre formas de cultivo. Os dados representam a média \pm SD de quatro repetições 
e se tornando amarelado (dados não mostrados), sugerindo que houve alteração no pH do meio. Esta alteração não foi observada no tratamento com $10^{-3} \mathrm{M}$ de SNP, provavelmente devido ao fato de que como houve diminuição do grau de expansão das células do cumulus, não ocorreu a síntese de ácido hialurônico (AH) que, como em suínos ${ }^{15}$, apresenta relação direta com a expansão das CC. No cultivo em placa não foi observado alteração na coloração do meio, demonstrando que uma maior proporção oócito/volume de meio de cultivo presente na placa (1 oócito/16,7 $\mu$ l de meio) versus a observada na gota (1 oócito/5 $\mu$ l de meio) previne a alteração do $\mathrm{pH}$ causada pela produção do ácido hialurônico, evento que ocorre durante a MIV, deixando o meio mais estável, além da presença de uma maior quantidade de substâncias antioxidantes disponíveis ao oócito e uma menor percentagem de substâncias oxidantes oriundas do metabolismo dos COC.

No presente experimento, foi demonstrado que não houve diferença na integridade da membrana das CC oriundas de COC cultivados em óleo ou placa, quando estas foram avaliadas pela coloração com laranja de acridina/brometo de etídio. Apesar desse resultado, os COC cultivados na placa se apresentaram mais homogêneos e mais claros quando comparados aos cultivados em óleo (dados não mostrados).

Ao se avaliar a integridade de membrana dos oócitos, foi observada diferença entre o sistema de cultivo nos grupo controle e $10^{-3} \mathrm{M}$ de SNP, no qual o cultivo em placa apresentou um melhor resultado. Contudo, essa diferença não foi observada no grupo $10^{-5} \mathrm{M}$ de SNP. Este resultado pode ser explicado pelo fato do grupo controle nesta forma de cultivo ter apresentado $100 \%$ de integridade na membrana plasmática em relação ao resultado observado no culttvo em óleo (91,3 $\pm 3,1 \%)$. Assim, a adição de $10^{-5} \mathrm{M}$ de SNP na placa não tinha como aumentar a integridade da membrana plasmática do oócito, como ocorreu na gota. Contudo, os COC cultivados em placa tratados com $10^{-3} \mathrm{M}$ de SNP apresentaram uma integridade de membrana maior do que os cultivados em gota, provavelmente pela maior relação entre oócito/meio. Os dados observados sugerem que o cultivo em placa proporciona um ambiente mais favorável para o cultivo de COC bovino do que em gota. No presente experimento, foram comparadas somente formas de cultivo utilizadas na rotina dos laboratórios que realizam fertilização in vitro. Visto que não foram isolados os grupos experimentais placa com óleo e sem óleo, e proporção de número de oócitos/volume de meio, outros experimentos devem ser realizados com este intuito.

A adição de $10^{-3} \mathrm{M}$ de SNP no meio de maturação inibiu a extrusão do primeiro $\mathrm{CP}$, corroborando com os resultados obtidos por Viana et al. ${ }^{5}$ que demonstraram que a adição da mesma concentração de SNP no meio de maturação sob óleo mineral inibe a progressão da meiose de oócitos bovinos. Juntos, esses dados sugerem que a adição de alta concentração de NO no meio de maturação induz à morte celular e consequente ausência da expansão das células do cumulus, ocorrendo assim alteração na maturação de oócitos bovinos.

A concentração de NO no meio de maturação do grupo controle e $10^{-5} \mathrm{M}$ de SNP no cultivo sob óleo mineral foi maior do que no da placa devido ao fato de que na placa existe maior proporção de oócito/ meio $(1 / 16,7)$, fazendo com que o NO produzido pelo COC estivesse mais diluído no meio. Porém, isto não ocorreu quando se adicionou $10^{-3} \mathrm{M}$ de SNP, no qual não foi observada diferença entre os tipos de cultivo, sugerindo que o NO migra para o óleo somente após alcançar um determinado grau de saturação no meio de maturação; não alterando assim os efeitos do NO sobre a MIV de COC bovinos cultivados em gota.

A presença de morte celular nas CC cultivadas em placa ou em gota e a constatação de que a adição da concentração de NO deletéria no meio de maturação não foi diferente entre os diferentes tipos de cultivo demonstram que a indução da morte celular pelo NO 
é independente do tipo de sistema de cultivo utilizado. Isso sugere que a ação do NO ocorre antes de sua migração para o óleo e/ou que o NO é metabolizado em uma molécula não lipossolúvel citotóxica.

\section{Referências}

1.FAES, M. R.; CALDAS-BUSSIERE, M. C.; VIANA, K. S.; DIAS, B. L.; COSTA, F. R.; ESCOCARD, R. M. Nitric oxide regulates steroid synthesis by bovine antral granulosa cells in a chemically defined medium. Animal Reproduction Science, v. 110, p. 222-236, 2009.

2. MATTA, S. G. C.; CALDAS-BUSSIERE, M. C.; VIANA, K. S.; FAES, M. R.; PAES DE CARVALHO, C. S.; DIAS, B. L.; QUIRINO, C. R. Effect of inhibition of synthesis of inducible nitric oxide synthase-derived nitric oxide by aminoguanidine on the in vitro maturation of oocyte-cumulus complexes of cattle. Animal Reproduction Science, v. 111, p. 189-201, 2008.

3. LEAL, A. C. M. S.; CALDAS-BUSSIERE, M. C.; PAES DE CARVALHO, C. S.; VIANA, K. S.; QUIRINO, C. R. Role of nitric oxide on quality of freshly ejaculated bull spermatozoa during heparin-induced in vitro capacitation. Animal Reproduction Science, v. 116, p. 38 - 49, 2009.

4. THALER, C. D.; EPEL, D. Nitric oxide in oocyte maturation, ovulation, fertilization, cleavage and implantation: a little dab'll do ya. Current Pharmaceutica Design, v. 9, p. 399-409, 2003.

5. VIANA, K. S.; CALDAS-BUSSIERE, M. C.; MATTA, S. G. C.; FAES, M. R.; PAES DE CARVALHO, C. S.; QUIRINO, C. R. Effect of sodium nitroprusside, a nitric oxide donor, on the in vitro maturation of bovine oocytes. Animal Reproduction Science, v. 102, p. 217-227, 2007.

6. GILCHRIST, R. B.; RITTER, L. J.; ARMSTRONG, D. T. Oocyte-somatic cell interactions during follicle development in mammals. Animal Reproduction Science, v. 82-83, p. 431446, 2004.

7. FATEHI, A. N.; ZEINSTRA, E. C.; KOOIJ, R. V.; COLENBRANDER, B.; BEVERS, M. M. Effect of cumulus cell removal of in vitro matured bovine oocytes prior to in vitro fertilization on subsequent cleavage rate. Theriogenology, v. 57, p. 1347-1355, 2002.

8. KA, H. H.; SAWAI, K.; WANG, W. H.; IM, K. S.; NIWA, K. Amino acids in maturation medium and presence of cumulus cells at fertilization promote male pronuclear formation in

\section{Agradecimentos}

Esse trabalho foi financiado pela FAPERJ (E26/171.059/2005). K.S. Viana recebeu bolsa de doutorado da CAPES.

porcine oocytes matured and penetrated in vitro. Biology of Reproduction, v. 57, p. 478-483, 1997.

9. SHIMADA, M.; ZENG, W.; TERADA, T. Inhibition of PI 3-kinase or MEK leads to suppression of p34cdc2 kinase activity and meiotic progression beyond the MI stage in porcine oocytes surrounded with cumulus cells. Biology of Reproduction, v. 65, p. 442-448, 2001.

10.KORHONEN, K.; KANANEN, K.; KETOJA, E.; MATOMAKI, J.; HALMEKYTO, M.; PEIPPO, J. Effects of serum-free in vitro maturation of bovine oocytes on subsequent embryo development and cell allocation in two developmental stages of day 7 blastocysts Reproduction in Domestic Animals, v. 44, n. 1, p. 42-49, 2009. doi: 10.1111/j.1439-0531.2008.01203.x

11.OKAWARA, S.; HAMANO, S.; TETSUKA, M. Bovine oocytes and early embryo express mRNA encoding glycerol kinase but addition of glycerol to the culture media interferes with oocyte maturation. Journal of Reproduction and Development, v. 55, p. 177-182, 2009.

12.FUNAHASHI, H.; CANTLEY, T. C.; STUMPF, T. T.; TERLOUW, S. L.; DAY, B. N. Use of low-salt culture medium with elevated oocyte glutathione levels and enhanced male pronuclear formation after in vitro fertilization. Biolology of Reproduction, v. 51, p. 633-639, 1994.

13.TAO, Y.; XIA, G.; BO, S.; ZHOU, B.; ZHANG, M.; WANG, F. Nitric oxide exerts different functions on porcine oocytes cultured in different models, which is affected by betamercaptoethanol. Asian-Australisian Journal of Animal Science, v. 17, p. 317-324, 2004.

14. RICART-JANE， D; LLOBERA， M.; LÓPEZ-TEJERO, M. Anticoagulants and others preanalytical factors interfer in plasma nitrate/nitrite quantification by Griess method. Nitric Oxide, v. 6, p. 178-185, 2002.

15.YOKOO, M.; KIMURA, N.; ABE, H.; SATO, E. Influence of hyaluronan accumulation during cumulus expansion on in vitro porcine oocyte maturation. Zygote, v. 16, p. 309-314, 2008. 